INTERNATIONAL HIGHER EDUCATION Number 74 Winter 2014

Pages 6-8

\title{
The Abdication of Thinking Capacity in International Higher
}

\section{Education}

\author{
PHILIP G. ALTBACH
}

Philip G. Altbach is Research Professor and director of the Center for International Higher Education. E-mail: altbach@bc.edu.

For almost a half century, several international governmental organizations consistently provided both a forum for discussions about global higher education issues and some capacity for policy analyses and supporting research. These organizations produced policy documents, published monographs, books and journals, sponsored international meetings, and from time to time financed and coordinated research projects on key international issues. They also collected statistics and occasionally issued policy documents relating to global and regionwide higher education issues. Perhaps most important, they provided forums for discussion, which brought together higher education leaders, researchers, and often government officials concerned with higher education. The ability to work on a global scale and to bring together multiple constituencies is of special significance, especially for such complex endeavor as higher education and research.

There is sufficient evidence to note that in the past few years, two of the leading international governmental organizations involved in these activities, UNESCO and the Organization for Economic Cooperation and Development (OECD) have largely left the field of higher education, leading a considerable 
vacuum. Only the World Bank, a latecomer to the area with activities largely limited to occasional policy studies and some research activities, seems to remain active.

This abdication is quite unfortunate since higher education more than ever needs "thinking capacity," analysis of contemporary issues, and "convening authority" for conversations and debates. It is also quite surprising, since higher education has never been more important to countries worldwide. Further, academic institutions and systems are increasingly affected by global trends that require comparative analysis and international debate and can benefit from an analysis of "best practice" worldwide.

\section{The Past AND Present}

UNESCO at one time played a useful role in higher education, despite its wellknown reputation for bureaucracy and inefficiency. It was the only organization in the world with full global coverage. It was able to attract representations from the developing countries as well as industrialized nations. In some countries, UNESCO had a unique connection with top governmental officials. Several of its regional offices built capacity for higher education research and policy analysis in eastern and central Europe, especially serious during the Cold War period, and in Latin America. Several journals provided an outlet for analysis and debate, such as Higher Education in Europe, published by the UNESCO European Centre for Higher Education (UNESCO-CEPES), which was closed in 2010. Particularly surprising was closing down Higher Education in Europe and not permitting an interested and well-respected publisher to continue it. UNESCO's two world conferences on higher education (held in 1998 and 2009) and several 
regional meetings were useful-being the forums that brought together government officials, university leaders, and researchers. In the past decade, this entire infrastructure has been systematically dismantled.

OECD, although its basic responsibility was mainly limited to membership in the industrialized world, also played an active and quite useful role. Its program on Institutional Management in Higher Education sponsored annual conferences for academic leaders on relevant topics and published a highly regarded international journal, Higher Education Policy. The journal was suddenly abolished, again with no thought of handing it to a publisher. OECD also sponsored a number of research projects, such as an analysis of emerging higher education trends in 2030, which resulted in useful books and conferences. All of this seems to be gone, as OECD has moved away from a concern for higher education. Emblematic for this development is the current situation of Assessment of Higher Education Learning Outcomes; after conducting a feasibility study, this ambitious initiative has been put on hold but in reality closed down.

Both organizations, and also the World Bank, from time to time sponsored major reports on key higher education themes. Examples included Peril and Promise, and others. These thoughtful and globally concerned documents sometimes had a significant impact on national policy and more broadly on global thinking about higher education. Although some of UNESCO's global higher education initiatives were of mixed quality and with regularly insufficient funding, they brought together almost all countries to think about higher education issues. Major documents and reports were prepared for them. 


\section{A KNOWLEDGe BASE}

It is rightly argued that in a majority of cases, the principal function of international organizations consists of legislative and standard-setting activities, policy advocacy, and policy advising, as well as the launching and implementation of various operational projects; and those activities imply the need for in-house expertise. The "standardization work" undertaken by UNESCO and OECD, in collaboration with other organizations, has been essential for collecting comparative educational statistics. UNESCO collects a range of statistics concerning education, with some coverage of higher education. These efforts had the advantage of global coverage but the disadvantage of only modest accuracy, due in part on a lack of capacity at UNESCO and on the reliance of what was provided by governments around the world. One has the impression that there is less attention to statistics now. OECD statistics tended to be more accurate and comprehensive but covered only the OECD-member countries, with a few additional ones added.

\section{IMPLICATIONS OF ABDiCATION}

Unfortunately, no other organizations offer the services or the broad perspectives that have disappeared with the abdication of UNESCO and OECD. The World Bank continues its small-scale concern with global higher education issues but does not sponsor meetings or involve relevant stakeholders. A large number of regional and single-purpose conferences take place, such as Shanghai Jiao Tong University's biannual World Class University meeting. The British Council's Going Global conference and the Qatar Foundation's WISE conference bring 
together a smaller number of participants but seem to have no key themes and little, if any, lasting significance.

Organizations such as the European Association for International Education attract an increasing number of global participants to their annual meetings. However, in general, such organizations are concerned with specific aspects of higher education, such as in EAIE's case with the theme of internationalization and student mobility or in case of the International Ranking Expert Group Observatory on university rankings.

Agencies and funders are typically driven by the current "hot topic" or fad in higher education. The current concern about "workforce training" and employability of graduates is a case in point: a few agencies and foundations have taken an interest in these themes with an international perspective, but they do not have a global view nor an interest in creating a knowledge base for international discussion. One can predict that the next set of ad hoc conferences and short-term research projects may be on massive open online courses and other elements of distance education. While these short-term concerns are certainly relevant and deserve attention, nothing can replace continuing investment in a broad international perspective on global higher education.

\section{SOLUTIONS}

This solution to the problem of a lack of "convening authority" and "thinking capacity" is not rocket science. It would be best, of course, if an international organization with appropriate resources and broad acceptability, among relevant global constituencies could undertake this responsibility; but, this seems unlikely. It might be possible for an arrangement like the TIMSS and PIRLS 
Center at Boston College, which coordinates the periodic mathematics and science evaluations, is funded by a number of agencies and has been able to remain active over more than a decade to undertake the task. Perhaps a group of regional and national higher education organizations could combine for this task. Perhaps the Qatar Foundation or a similar organization with considerable resources could underwrite a serious higher education initiative that would go beyond occasional conferences. There is a desperate need for ongoing international debate, discussion, and regular data collection on higher education. At present, we have only a fragmented picture at best. 